\title{
Association between age of first exposure and heavy internet use in a representative sample of 317,443 adolescents from 52 countries
}

DOI:

10.1007/s00787-021-01869-5

\section{Document Version}

Final published version

Link to publication record in Manchester Research Explorer

Citation for published version (APA):

López-Bueno, R., Koyanagi, A., López-Sánchez, G. F., Firth, J., \& Smith, L. (2021). Association between age of first exposure and heavy internet use in a representative sample of 317,443 adolescents from 52 countries. European Child and Adolescent Psychiatry. https://doi.org/10.1007/s00787-021-01869-5

Published in:

European Child and Adolescent Psychiatry

\section{Citing this paper}

Please note that where the full-text provided on Manchester Research Explorer is the Author Accepted Manuscript or Proof version this may differ from the final Published version. If citing, it is advised that you check and use the publisher's definitive version.

\section{General rights}

Copyright and moral rights for the publications made accessible in the Research Explorer are retained by the authors and/or other copyright owners and it is a condition of accessing publications that users recognise and abide by the legal requirements associated with these rights.

\section{Takedown policy}

If you believe that this document breaches copyright please refer to the University of Manchester's Takedown Procedures [http://man.ac.uk/04Y6Bo] or contact uml.scholarlycommunications@manchester.ac.uk providing relevant details, so we can investigate your claim.

\section{OPEN ACCESS}




\title{
Association between age of first exposure and heavy internet use in a representative sample of 317,443 adolescents from 52 countries
}

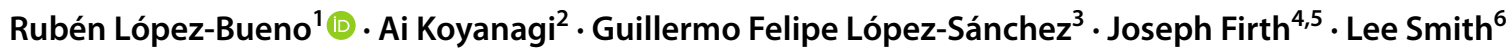

Received: 18 April 2021 / Accepted: 21 August 2021

(c) The Author(s) 2021

\begin{abstract}
Internet usage among adolescents has increased substantially over the last years, concurrently with emerging concerns that an abusive use is associated with detrimental health outcomes. Our objective was to examine the association between age of first exposure and heavy Internet usage in different domains. Data from the 2018 wave of the Programme for International Student Assessment (PISA) were retrieved. This included a total of 317,443 participants (49.2\% boys) aged 15 and 16 years from 52 countries. Data from both Internet use and age of first exposure were retrieved and used to conduct metanalyses with random effects. Adolescents reporting an age of first exposure of Internet usage at $\geq 13$ years old had the lowest odds for heavy Internet use ( $>2 \mathrm{~h}$ /day) (reference group: $\leq 9$ years) during weekends (odds ratio, 0.41 [95\% CI, 0.35-0.48]), weekdays (odds ratio, 0.45 [95\% CI, 0.37-0.56]), and during school time (odds ratio (odds ratio, 0.86 [95\% CI, 0.77-0.96]) even when adjusted for sex, socioeconomic status, and country. A stronger association was observed in adolescents from South and Central America and Eastern Mediterranean regions in the domain of weekends and weekdays. The results indicate that early internet exposure is associated with heavy Internet use, particularly during weekends and weekdays, regardless the geographical region, in a linear fashion. Further research should aim to examine if better education and parental control in specific areas may avoid excessive Internet use that possibly have a negative influence on both mental and physical health.
\end{abstract}

Keywords Social media $\cdot$ Video games $\cdot$ Addictions $\cdot$ Mental health $\cdot$ Health habits

\section{Introduction}

Internet use has been incorporated into almost every facet of life. For example, the internet is used for communication via emails, video calls, and instant messages; for entertainment, such as gaming, streaming TV shows, and music; and for work/education by providing a source of instant knowledge and information searching. The present generation of adolescents has simultaneously aged with the introduction and expansion of tablets and smartphones and the rise of social networks, which comprises activities, such as communicating, gaming, listening to music, or searching information, among others. The time US adolescents go online more than doubled between 2006 and 2016, and similar figures have been observed in other Western countries [1]. In view of this, a plethora of studies have investigated excessive internet use in adolescents, observing a predominant link to individual factors, such as gender, self-control, social anxiety or self-esteem among others, and prevalence ranging up to a maximum of $26 \%[2,3]$. 
Worryingly, detrimental effects of excessive Internet use have been associated with various detrimental health outcomes observed in adolescents; a longitudinal study by Lam et al. including adolescents initially free of mental health complications identified pathological use of the Internet as a risk factor for depression [4]. Also, a more recent study involving British adolescents showed excessive use of Internet associated with conduct problems, hyperactivity, poorer physical health, depression, and impact on daily life activities [5]. Moreover, a dose-time-response association between the use of social media and an increase in symptoms of depression, conduct problems, and episodic heavy drinking has been previously identified [6]. It should also be noted however that other studies have found limited evidence of adverse psychological effects from Internet usage in general [7], and causal mechanisms of the observed associations so far have yet to be established.

Nonetheless, there is also growing evidence of an association between intensive Internet use and worse physical health outcomes; Cassidy-Bushrow et al. [8] observed heavy internet usage (i.e., $\geq 2 \mathrm{~h} /$ day) in adolescents associated with significantly higher odds for elevated blood pressure compared to light Internet users. Furthermore, Internet use for more than $2 \mathrm{~h}$ at weekends was the only explanatory variable remaining for overweight after 2-year follow-up [9]. Moreover, Internet use for non-study reasons has been identified as an important reason for increased sedentary behaviour in European adolescent girls, which in turn can favour obesity and other related conditions [10].

Given this background, it seems of growing importance to investigate which factors might lead to heavy Internet use in different domains. One potential variable that deserves closer examination is age of first exposure, since age of initiation has been associated with problematic use of Internet in elementary school children and Internet gaming disorder [11, 12]. Currently however, there is little evidence concerning whether an early exposure might be associated with heavy Internet use in adolescence. Indeed, there is a lack of studies examining the consistence of the aforementioned association in different domains in large samples worldwide. Therefore, this study aims to investigate the association between age of first exposure and heavy Internet use in a large, representative, and widespread sample of adolescents from 52 countries.

We hypothesised that an inverse association will be observed between age of first exposure and heavy use of the Internet in adolescents, with potential differences concerning domains and geographical regions.

\section{Methods}

\section{Study population and data source}

The Organisation for Economic Co-operation and Development (OECD) systematically conducts a Programme for
International Students Assessment (PISA) every 3 years since 2000. A total of 79 countries, including OECD and nonOECD members, participated in the latest round of PISA in 2018. Of those, only countries implementing both the Student Questionnaire, which was compulsory in the PISA 2018 main survey, and the optional Familiarity Questionnaire, which contained the main examined variables, were included in the present study (i.e., 52 countries overall). This comprised an in-school representative population of students aged between 15 years and 3 months and 16 years and 2 months at the time of assessment, or a one-month variation of this. Except for Russia, where a three-stage design first considering geographical regions was used, PISA was based on a two-stage probabilistic, stratified, and clustered survey design for the participating countries. First, schools were stratified and then a minimum of 150 schools with probability proportional to size were randomly selected from within each country. The second-stage sampling was aimed at students within sampled schools; from each list of eligible students within a school, either a sample of 42 or 35 students were selected with equal probability for computer and paper-based assessments, and for lists with fewer students than that target number, all students on the list were selected. Included countries aimed for a response rate of $85 \%$ for schools and $80 \%$ for students. Further details of both the complex survey and sampling design are available in the 2018 Technical Report [13].

Data retrieved from the public anonymized dataset derived from PISA questionnaires were used for the present study. Participants with complete values in all the variables used in this study (84\%) were included in the analyses.

Countries were grouped into seven categories according to the World Health Organization (WHO) regions and subregions. Sub-regions are denoted by A, B and C suffices, which corresponds to a declining country-level wealth [14]. The seven categories used were the following: (1) Americas A (United States); (2) Americas B/C; (3) Eastern Mediterranean; (4) Europe A; (5) Europe B/C; (6) South-East Asian and Western Pacific; and (7) Africa (Morocco). Southeast Asian and Western Pacific regions were combined since Thailand was the only PISA participant in the former. Although Chinese Taipei and Hong Kong are not currently recognized as WHO member states, they were included into the Southeast Asian and Western Pacific region according to geography.

The study received the approval of the Ethics Committee of Research in Humans of the institution (register code 1510464), and adhered to the STROBE Statement recommendations [15].

\section{Age of first exposure to Internet}

The exposure variable was self-reported by participants through the following question: "How old were you when 
you first accessed the Internet?" Answers comprised the following options: " 3 years old or younger", "4-6 years old", "7-9 years old", "10-12 years old", "13 years old or older", and "I have never accessed the Internet". To attenuate the possibility of a recall bias for those reporting earlier exposure ages, this variable was later categorized into those having initiated the Internet at age 9 or lower, from 10 to 12 years, and 13 years or over.

\section{Heavy Internet use}

The outcome variable was self-reported by participants through the following questions: "During a typical weekday, for how long do you use the Internet at school?", "During a typical weekday, for how long do you use the Internet outside of school?", "On a typical weekend day, for how long do you use the Internet outside of school?" Potential answers comprised "No time", "1-30 min per day", "31-60 min per day", "Between 1 and $2 \mathrm{~h}$ per day", "Between 2 and $4 \mathrm{~h}$ per day", "Between 4 and $6 \mathrm{~h}$ per day", and "More than $6 \mathrm{~h}$ per day". According to prior research, use of the Internet was categorized into those who used it from no time to $2 \mathrm{~h}$, and those who used from more than $2 \mathrm{~h}$ (heavy Internet use) in each of the three examined domains (i.e., at school, during weekdays, and during weekends) [16].

\section{Socioeconomic status}

Prior research has identified inverse associations between Internet use and socioeconomic status (SES), and thus SES was incorporated into statistical models as a control variable [17]. Reported family wealth possessions, a continuous variable estimated using OECD item response theory scaling including nine standardised questions about possessions in and characteristics of the home, served to estimate SES. These included questions on whether the student had their own room, whether the home had a link to the Internet, the number of rooms in the home with a bath or shower, the number of televisions, computers, tablets, cell phones, and e-book readers in the home, and the number of cars the family has. Quintiles of this variable were calculated to use in our analyses.

\section{Statistics}

Statistical analyses were conducted with Stata 16.1 (Stata Corp LP, College station, Texas). Multivariable logistic regression analysis was performed to assess the association between age of first exposure to Internet (exposure variable) and heavy Internet use in three different domains (outcome variables). Survey-adjusted analyses using weighted sample (eTable 1 in the Supplement) overall, as well as stratified by geographical region were conducted (eTable 2). These analyses were adjusted for sex, SES, and country. To assess the generalizability of the findings based on the overall sample and regional sub-samples, we also conducted country-wise regression analyses for the association between age of first exposure to Internet and heavy Internet use adjusted for sex and SES. Pooled estimates for each age category were obtained by metanalyses with random effects based on region-wise estimates. To assess the level of heterogeneity among regions in the examined association we also calculated the Higgins's $I^{2}$. All variables were included in the models as either continuous (SES) or categorical variables. Results from the logistic regression analyses are presented as odds ratios (ORs) with $95 \%$ confidence intervals (CIs). Sensitivity analyses examining the association stratified for sex, SES, and country using the original categories for age of first exposure to Internet were performed to check the robustness of the findings (eTable 3 , eTable 4, eTable 5). Additionally, the aforementioned association was also examined using the final adjusted model with the original categories of age of first exposure to Internet and heavy use of the Internet variables using linear regression for the last case.

\section{Results}

A total of 317,443 adolescents aged 15 and 16 years from 52 countries constituted the final sample, of whom 161,148 were girls (50.8\%). Data on heavy Internet use during weekdays, weekends, and school time, as well as SES and first exposure to Internet use are reported in Table 1 . The majority of students reported Internet exposure at $\leq 9$ years old (60.3\%).

In total, 212,395 (66.9\%) and 244,621 (77.1\%) adolescents, respectively, reported heavy Internet use during weekdays and weekends, excluding school time. In addition, 73,474 (23.2\%) adolescents reported heavy Internet use in school. Information on prevalence of heavy Internet use for each country is shown in Table 2. The highest prevalence of heavy Internet use during weekdays (85.4\%) and weekends (91.8\%) was observed in Sweden, whereas the highest prevalence for heavy Internet use in school was observed in Denmark (70.5\%).

Figure 1 displays overall and region-wise estimates for heavy Internet use during weekends. Overall, exposure to Internet at 10 years old or over was associated with significantly lower odds for heavy Internet use during weekends at 15 or 16 years old (odds ratio, 0.53 [95\% CI, 0.45-0.62]). Subgroup of adolescents reporting age of Internet initiation at $\geq 13$ years showed the highest inverse association (odds ratio, 0.41 [95\% CI, 0.35-0.48]), which was more accentuated in countries from America B/C (odds ratio, 0.32 [95\% CI, 0.29-0.36]), and Eastern Mediterranean region (odds ratio, 0.32 [95\% CI, 0.27-0.38]). 
Table 1 Sample characteristics (overall and by heavy Internet use) $(N=317,443)$

\begin{tabular}{|c|c|c|c|c|c|}
\hline Characteristic & Category & Overall & $\begin{array}{l}\text { Heavy Internet use } \\
\text { during weekdays }\end{array}$ & $\begin{array}{l}\text { Heavy Internet use } \\
\text { during weekends }\end{array}$ & $\begin{array}{l}\text { Heavy Internet } \\
\text { use in the school }\end{array}$ \\
\hline \multirow[t]{3}{*}{ Age of first exposure to Internet } & 9 years or lower & 60.3 & 71.8 & 81.6 & 25.0 \\
\hline & $10-12$ years & 30.7 & 63.1 & 74.0 & 20.6 \\
\hline & 13 years or over & 9.0 & 47.6 & 57.5 & 19.2 \\
\hline \multirow[t]{2}{*}{ Sex } & Boys & 49.2 & 65.5 & 75.6 & 22.6 \\
\hline & Girls & 50.8 & 68.3 & 78.5 & 23.7 \\
\hline \multirow[t]{7}{*}{ Region } & Americas A & 1.3 & 77.5 & 82.6 & 38.6 \\
\hline & Americas B/C & 11.6 & 66.2 & 72.0 & 21.8 \\
\hline & Eastern Mediterranean & 7.8 & 62.7 & 72.8 & 17.9 \\
\hline & Europe A & 32.9 & 73.0 & 82.9 & 23.0 \\
\hline & Europe B/C & 25.0 & 64.2 & 73.3 & 24.7 \\
\hline & $\begin{array}{l}\text { Southeast Asian and West- } \\
\text { ern Pacific }\end{array}$ & 19.9 & 64.2 & 78.8 & 24.0 \\
\hline & Africa & 1.5 & 30.5 & 44.8 & 13.5 \\
\hline \multirow[t]{5}{*}{ Socioeconomic status } & First quintile & 15.3 & 50.7 & 61.3 & 18.0 \\
\hline & Second quintile & 16.1 & 63.9 & 74.8 & 20.2 \\
\hline & Third quintile & 20.5 & 67.4 & 78.2 & 21.6 \\
\hline & Fourth quintile & 20.1 & 70.7 & 80.8 & 23.7 \\
\hline & Fifth quintile & 28.0 & 74.3 & 83.4 & 28.4 \\
\hline
\end{tabular}

Regarding heavy Internet use during weekdays (Fig. 2), overall values for the subgroup of adolescents whose first Internet exposure age was $\geq 10$ years, showed a significant lower odds ratio (0.57 [95\% CI, 0.50-0.66]). The subgroup of adolescents aged 13 years and above showed lower odds ratio $(0.45$ [95\% CI, $0.37-0.56]$ ), with countries from the America $\mathrm{B} / \mathrm{C}$ region displaying the lowest values (odds ratio, 0.31 [95\% CI, 0.28-0.35]).

Figure 3 presents estimates concerning heavy Internet use in school. Overall values showed lower significant odds (odds ratio, 0.86 [95\% CI, 0.82-0.91]), with similar values for the 10-12 years old (odds ratio, 0.86 [95\% CI, 0.82-0.89]), and the 13 years and above subgroup (odds ratio, 0.86 [95\% CI, 0.77-0.96]). African adolescents whose age of first exposure to Internet use was 13 years or above showed the lowest odds for heavy use of the Internet in the school (odds ratio, 0.58 [95\% CI, 0.46-0.74]).

Sensitivity analyses showed similar results for the examined association using the original age of first exposure to Internet categories as well as for the original categories for heavy use of the Internet in the three domains.

\section{Discussion}

To our knowledge, this is the first study analysing age of Internet initiation and heavy Internet use among adolescents from a large international sample. The prevalence of heavy Internet use during both weekends and weekdays outside schools remained consistently higher for those adolescents with an earlier age of first exposure to the Internet, in a significant linear fashion in the examined geographical regions. However, these trends were not completely confirmed for less represented geographical areas, such as Africa and Americas A, with regard to school time internet usage. Prevalence of heavy Internet use was substantially higher during weekends and weekdays in relation to school time, which also showed significant higher odds of heavy use of the Internet overall for those whose first Internet exposure age was $\leq 9$ years old. In particular, both Eastern Mediterranean and America $\mathrm{B} / \mathrm{C}$ regions pointed at a stronger negative association between earlier age of first exposure and heavy Internet use during weekends and weekdays outside of school, and during school time, although the latter was importantly less accentuated. These results support the notion of a widespread potential link between age of first exposure and heavy Internet use during adolescence. Within this, the findings further indicate that these associations vary with regards to the examined domain (i.e., the association is more pronounced during weekends and weekdays outside the school than during school time), and the geographical region.

A study by Martins et al. [18] observed a negative association between Internet addiction in adolescents and parental control. Hence, parental control may play a critical role when modulating the use of Internet among adolescents and could help to explain the lower prevalence found for 
Table 2 Sample size and prevalence of heavy Internet use by country

\begin{tabular}{|c|c|c|c|c|c|c|}
\hline Geographical areas & Country & $N$ & Female $(\%)$ & $\begin{array}{l}\text { Heavy Internet use } \\
\text { during weekdays (\%) }\end{array}$ & $\begin{array}{l}\text { Heavy Internet use } \\
\text { during weekends (\%) }\end{array}$ & $\begin{array}{l}\text { Heavy Internet use } \\
\text { in the school }(\%)\end{array}$ \\
\hline & Overall & 317,443 & 50.8 & 66.9 & 77.1 & 23.2 \\
\hline Americas A & United States & 4081 & 49.9 & 77.5 & 82.6 & 38.6 \\
\hline \multirow[t]{7}{*}{ Americas B/C } & Brazil & 7450 & 52.6 & 71.6 & 76.6 & 14.6 \\
\hline & Chile & 6016 & 49.8 & 77.5 & 83.9 & 32.1 \\
\hline & Costa Rica & 5887 & 50.8 & 72.5 & 77.2 & 31.7 \\
\hline & Dominican Republic & 4063 & 51.8 & 53.2 & 59.2 & 14.1 \\
\hline & Mexico & 5792 & 52.3 & 57.3 & 60.7 & 17.4 \\
\hline & Panama & 4264 & 49.6 & 48.7 & 62.8 & 11.0 \\
\hline & Uruguay & 3328 & 53.8 & 76.6 & 78.0 & 32.7 \\
\hline \multirow[t]{5}{*}{ Eastern Mediterranean } & Albania & 5295 & 50.4 & 47.4 & 59.6 & 10.1 \\
\hline & Croatia & 5879 & 51.6 & 69.7 & 82.1 & 22.9 \\
\hline & Malta & 2764 & 52.5 & 76.8 & 83.0 & 10.9 \\
\hline & Serbia & 4909 & 51.6 & 74.4 & 79.2 & 23.4 \\
\hline & Turkey & 6125 & 49.7 & 53.5 & 65.6 & 18.5 \\
\hline \multirow[t]{14}{*}{ Europe A } & Austria & 6009 & 50.6 & 68.9 & 76.5 & 23.5 \\
\hline & Belgium & 7042 & 51.8 & 75.1 & 87.2 & 16.8 \\
\hline & Denmark & 6280 & 51.5 & 81.5 & 89.7 & 70.5 \\
\hline & Finland & 4956 & 50.5 & 75.1 & 85.6 & 25.8 \\
\hline & France & 5411 & 49.7 & 68.6 & 83.3 & 16.7 \\
\hline & Greece & 5466 & 51.5 & 65.4 & 81.0 & 20.5 \\
\hline & Iceland & 2754 & 52.3 & 74.2 & 84.5 & 30.9 \\
\hline & Ireland & 5062 & 50.6 & 74.8 & 85.6 & 9.8 \\
\hline & Italy & 10,024 & 49.4 & 70.2 & 71.0 & 19.7 \\
\hline & Luxembourg & 4440 & 49.1 & 73.9 & 82.9 & 22.9 \\
\hline & Spain & 30,448 & 50.7 & 71.6 & 83.4 & 16.5 \\
\hline & Sweden & 4580 & 51.9 & 85.4 & 91.8 & 52.1 \\
\hline & Switzerland & 5035 & 48.5 & 64.4 & 76.0 & 17.5 \\
\hline & United Kingdom & 6787 & 51.5 & 81.2 & 89.4 & 15.0 \\
\hline \multirow[t]{14}{*}{ Europe B/C } & Bulgaria & 3638 & 50.8 & 71.5 & 76.0 & 36.0 \\
\hline & Czech Republic & 6124 & 50.7 & 62.1 & 71.7 & 16.3 \\
\hline & Estonia & 4770 & 51.2 & 72.1 & 79.4 & 28.5 \\
\hline & Georgia & 3972 & 51.3 & 60.6 & 69.0 & 11.5 \\
\hline & Hungary & 4687 & 51.3 & 71.7 & 82.1 & 23.5 \\
\hline & Kazakhstan & 17,084 & 50.1 & 50.7 & 63.3 & 24.3 \\
\hline & Latvia & 4589 & 51.4 & 73.8 & 79.5 & 28.1 \\
\hline & Lithuania & 6082 & 50.3 & 73.9 & 78.4 & 23.5 \\
\hline & Poland & 5108 & 51.8 & 72.9 & 82.6 & 23.7 \\
\hline & Russian Federation & 6341 & 52.1 & 67.2 & 76.3 & 28.4 \\
\hline & Slovak Republic & 4983 & 51.2 & 67.1 & 73.7 & 26.9 \\
\hline & Slovenia & 5496 & 48.1 & 59.1 & 70.9 & 21.3 \\
\hline & Moscow Region (RUS) & 1735 & 49.5 & 69.1 & 77.8 & 32.0 \\
\hline & Tatarstan (RUS) & 4715 & 52.1 & 64.4 & 72.5 & 30.7 \\
\hline
\end{tabular}


Table 2 (continued)

\begin{tabular}{|c|c|c|c|c|c|c|}
\hline Geographical areas & Country & $N$ & Female $(\%)$ & $\begin{array}{l}\text { Heavy Internet use } \\
\text { during weekdays (\%) }\end{array}$ & $\begin{array}{l}\text { Heavy Internet use } \\
\text { during weekends (\%) }\end{array}$ & $\begin{array}{l}\text { Heavy Internet use } \\
\text { in the school (\%) }\end{array}$ \\
\hline \multirow{10}{*}{$\begin{array}{l}\text { South-East Asian and } \\
\text { Western Pacific }\end{array}$} & Australia & 10.922 & 50.1 & 76.7 & 83.2 & 47.1 \\
\hline & Brunei Darussalam & 5590 & 50.8 & 68.1 & 71.3 & 6.8 \\
\hline & Chinese Taipei & 6499 & 50.0 & 55.7 & 78.4 & 20.1 \\
\hline & Hong Kong & 5401 & 50.3 & 66.2 & 78.9 & 8.7 \\
\hline & Japan & 5625 & 51.0 & 48.1 & 73.4 & 7.7 \\
\hline & Korea & 6283 & 48.4 & 43.3 & 69.0 & 8.2 \\
\hline & Macao & 3331 & 50.4 & 66.9 & 83.5 & 10.6 \\
\hline & New Zealand & 5474 & 52.2 & 77.8 & 83.5 & 48.0 \\
\hline & Singapore & 6168 & 49.0 & 73.1 & 84.3 & 21.0 \\
\hline & Thailand & 7943 & 54.7 & 60.7 & 80.3 & 33.7 \\
\hline Africa & Morocco & 4696 & 47.0 & 30.5 & 44.8 & 13.5 \\
\hline
\end{tabular}

Fig. 1 Regional-wise associations between age of first exposure to Internet (exposure) and heavy Internet use during weekend (outcome). OR odds ratio, CI confidence interval. Overall estimate was obtained by metaanalysis with random effects.

The model is survey-adjusted, weighted, and additionally adjusted for sex, country, and socioeconomic status

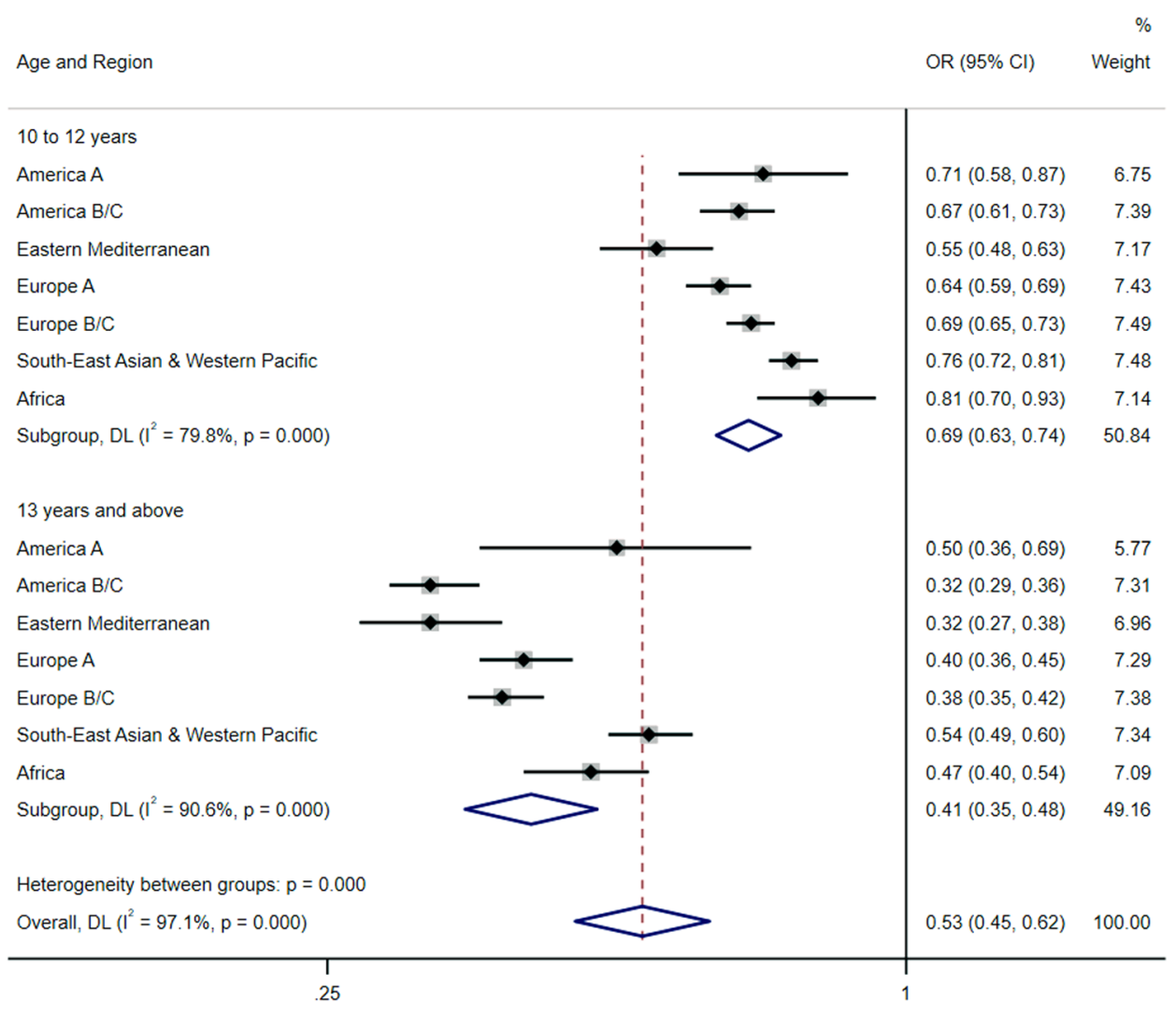

NOTE: Weights and between-subgroup heterogeneity test are from random-effects model heavy Internet use during school time, as schools are usually supervised environments which could persuade adolescents away from an indiscriminate use of the Internet. Furthermore, because parental control has been observed to vary among countries, this could partly explain geographical differences found in the present study. In particular, parental control has been observed to be higher in Eastern than Western countries [19] which is consistent with the higher prevalence of heavy Internet use during weekend and weekdays we found for America A and Europe A geographical areas. Moreover, since parental awareness regarding Internet use of adolescents has been found higher in mothers than fathers [20], it is plausible that those countries with higher prevalence of mothers involved in parental 
Fig. 2 Regional-wise associations between age of first exposure to Internet (exposure) and heavy Internet use during weekdays excluding school (outcome). $O R$ odds ratio, $C I$ confidence interval. Overall estimate was obtained by metaanalysis with random effects.

The model is survey-adjusted, weighted, and additionally adjusted for sex, country, and socioeconomic status

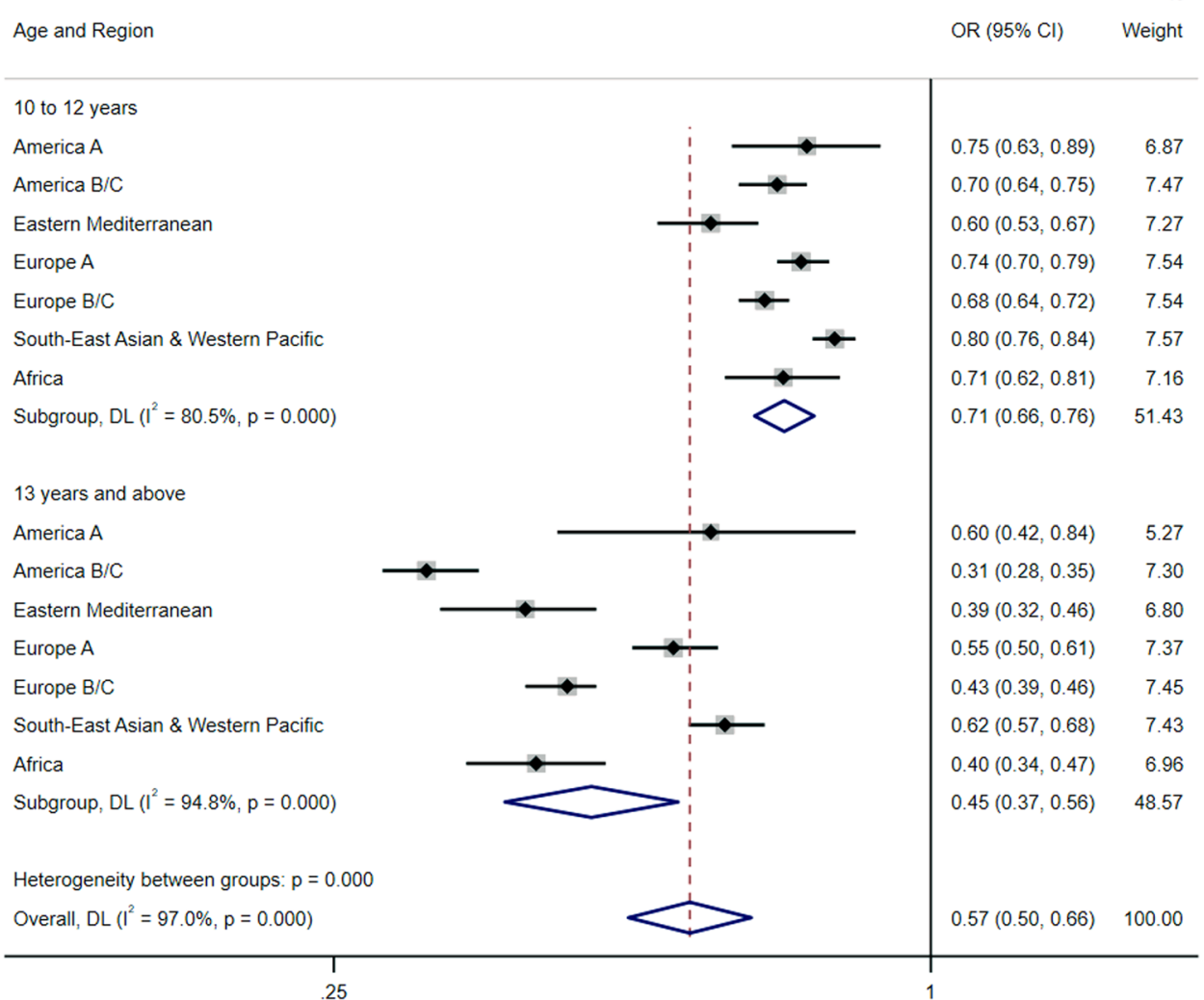

NOTE: Weights and between-subgroup heterogeneity test are from random-effects model

$\%$

Age and Region

$\mathrm{OR}(95 \% \mathrm{Cl})$

Weight

tions between age of first exposure to Internet (exposure) and heavy Internet use during school (outcome). $\mathrm{OR}$ odds ratio, $\mathrm{CI}$ confidence interval. Overall estimate was obtained by metaanalysis with random effects.

The model is survey-adjusted, weighted, and additionally adjusted for sex, country, and socioeconomic status

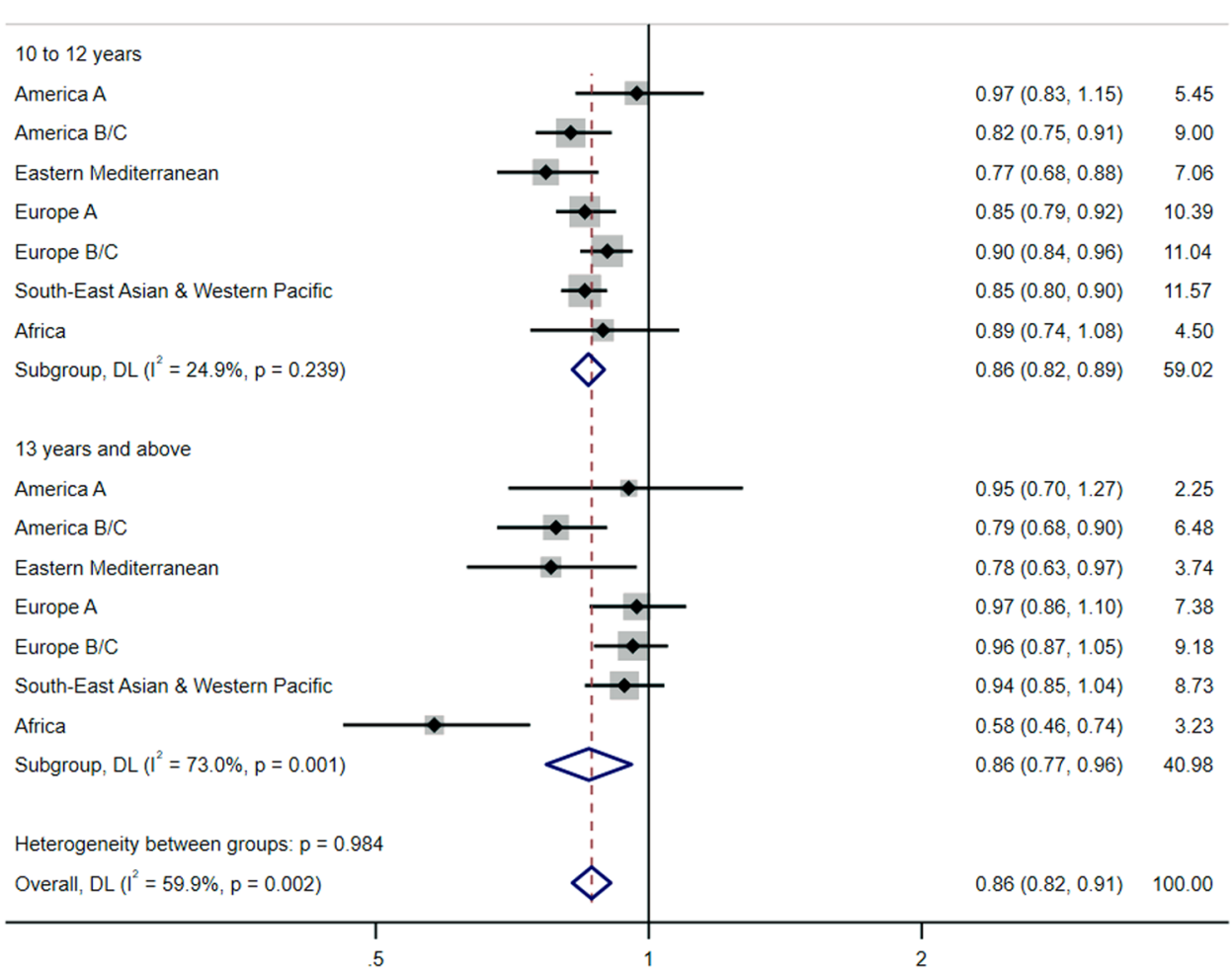

NOTE: Weights and between-subgroup heterogeneity test are from random-effects model 
control of children present lower heavy use of the Internet in adolescents.

In addition, the use of Internet for educational purposes (i.e., assignments requiring the use of Internet) has been previously observed to increase overall Internet use in highschool students. Therefore, countries with educational systems tending to higher number of assignments requiring the use of Internet may be more likely to have higher prevalence of heavy Internet use among their adolescent-schooled population [21]. In view of this, it would be plausible to consider those countries with higher accessibility to Internet as more prone to use the Internet in their educational schemes which, in turn, can importantly increase heavy use of the Internet among adolescents. This argument is coherent with the high prevalence of heavy Internet use of adolescents during school time and outside school at weekends and weekdays observed in this study for very high-income countries with supposedly full access to the Internet, such as Sweden or Denmark. On the other hand, the higher prevalence of heavy Internet use we found at weekends endorses the findings of previous research, which observed higher prevalence of sedentary behaviours in European adolescents usually associated with Internet use for not academic purposes [10].

Regarding the observed association between age of first exposure and heavy Internet use in adolescence, prior research observed more serious problematic Internet use in elementary school among Taiwanese children exhibiting earlier experiences of using the Internet [12]. This strengthens the possibility of an association between the two aforementioned study variables that might go back earlier than the age of 15 or 16 years. As it has been observed for younger children, those adolescents going online through more types of devices, might also have more serious problems with Internet use [12]. Nevertheless, our study observed a consistent negative association between age of use of initiation and heavy Internet use regardless of SES (defined in this study by the ownership of a number of items, including different digital devices) which indicates that the association is robust to this confounder. Similarly, sex does not seem to substantially modify our results since both adjusted and sensitivity analyses involving sex continue showing a strong association. By contrast, a Korean study observed the association between Internet addiction and adverse psychological health outcomes was more pronounced in boys than in girls [22], although the different outcomes used make comparisons with our study difficult.

The results of this study should be interpreted in the light of several limitations, including the possibility of a recall bias in the cross-sectional data, although the impact of this may have been attenuated through the large representative sample study used. Additionally, owing to the high percentage of missing participants from specific countries, there is still the possibility of a selection bias, although the widespread sample across 52 countries from 7 different geographical areas is enough to confirm the observed association. However, we found a higher heterogeneity among categories of age for first exposure to Internet in the different geographical regions, which might strengthen the notion that differences regarding geographical regions are critical. Moreover, the scope of the findings is limited, and does not allow to analyse whether there is any type of digital device, content, or an accurate year of initiation associated with higher consumption of the Internet. Further research might discriminate usage that can be detrimental for health from usage that can be health-enhancing, such as specific exposures to particular social networks that may improve relevant dimensions of adolescents' self-construction [23]. Also, because there is little information regarding either lowincome or African countries, generalizations over populations from countries with such features should be cautiously made. Moreover, because Africa and Americas A regions are substantially less represented in the study (i.e., lower number of participants from a single country), results of these regions should be interpreted with caution. Finally, because the current COVID-19 pandemic is affecting lifestyles worldwide, habits concerning Internet will have likely changed over this period, probably increasing the use of Internet among adolescents [24].

\section{Conclusion}

Adolescents whose age of first exposure to Internet was $\leq 9$ years exhibited significant higher odds for heavy use of the Internet during weekends, weekdays, and school time, although the latter was weaker. This association was stronger in adolescents from America B/C and Eastern Mediterranean countries, who might experience less parental control outside school than those from other geographical regions. To avoid excessive Internet usage as well as to inform preventive strategies, future research examining the causes underpinning the association between age of first exposure and heavy use of the Internet is warranted.

Supplementary Information The online version contains supplementary material available at https://doi.org/10.1007/s00787-021-01869-5.

Author contributions RL-B: conceptualization, software, data curation, writing — original draft preparation. LS: methodology, investigation, reviewing and editing. AK: supervision, methodology, reviewing and editing. JF: validation, reviewing and editing. GFL-S: investigation, reviewing and editing.

Funding Open Access funding provided thanks to the CRUE-CSIC agreement with Springer Nature. 
Availability of data and materials The technical report and the 2018 PISA dataset used in this study are publicly available at https://www. oecd.org/pisa/data/.

\section{Declarations}

Conflict of interest The authors declare that they have no conflict of interest.

Ethical approval This study got the approval of the Ethics Committee of Research in Humans of the University of Valencia (register code 1510464)

Consent to participate Participants gave informed consent to participate.

Consent for publication Participants gave consent for publication of anonymized data.

Open Access This article is licensed under a Creative Commons Attribution 4.0 International License, which permits use, sharing, adaptation, distribution and reproduction in any medium or format, as long as you give appropriate credit to the original author(s) and the source, provide a link to the Creative Commons licence, and indicate if changes were made. The images or other third party material in this article are included in the article's Creative Commons licence, unless indicated otherwise in a credit line to the material. If material is not included in the article's Creative Commons licence and your intended use is not permitted by statutory regulation or exceeds the permitted use, you will need to obtain permission directly from the copyright holder. To view a copy of this licence, visit http://creativecommons.org/licenses/by/4.0/.

\section{References}

1. Twenge JM, Martin GN, Spitzberg BH (2018) Trends in U.S. Adolescents' media use, 1976-2016: the rise of digital media, the decline of TV, and the (near) demise of print. Psychol Pop Media Cult 8:329-345. https://doi.org/10.1037/ppm0000203

2. Moreno MA, Jelenchick L, Cox E et al (2011) Problematic internet use among US youth: a systematic review. Arch Pediatr Adolesc Med 165:797-805. https://doi.org/10.1001/archpediatrics.2011.58

3. Anderson EL, Steen E, Stavropoulos V (2017) Internet use and problematic internet use: a systematic review of longitudinal research trends in adolescence and emergent adulthood. Int $\mathrm{J}$ Adolesc Youth 22:430-454. https://doi.org/10.1080/02673843. 2016.1227716

4. Lam LT, Peng Z-W (2010) Effect of pathological use of the internet on adolescent mental health. Arch Pediatr Adolesc Med 164:901-906. https://doi.org/10.1001/archpediatrics.2010.159

5. El Asam A, Samara M, Terry P (2019) Problematic internet use and mental health among British children and adolescents. Addict Behav 90:428-436. https://doi.org/10.1016/j.addbeh.2018.09.007

6. Brunborg GS, Burdzovic Andreas J (2019) Increase in time spent on social media is associated with modest increase in depression, conduct problems, and episodic heavy drinking. J Adolesc 74:201-209. https://doi.org/10.1016/j.adolescence.2019.06.013

7. Orben A (2020) Teenagers, screens and social media: a narrative review of reviews and key studies. Soc Psychiatry Psychiatr Epidemiol 55:407-414. https://doi.org/10.1007/s00127-019-01825-4

8. Cassidy-Bushrow AE, Johnson DA, Peters RM et al (2015) Time spent on the internet and adolescent blood pressure. J Sch Nurs 31:374-384. https://doi.org/10.1177/1059840514556772
9. Barrense-Dias Y, Berchtold A, Akre C, Surís JC (2016) The relation between internet use and overweight among adolescents: a longitudinal study in Switzerland. Int J Obes 40:45-50. https:// doi.org/10.1038/ijo.2015.146

10. Rey-López JP, Vicente-Rodriguez G, Ortega FB et al (2010) Sedentary patterns and media availability in European adolescents: The HELENA study. Prev Med (Baltim) 51:50-55. https://doi.org/ 10.1016/j.ypmed.2010.03.013

11. Beard CL, Haas AL, Wickham RE, Stavropoulos V (2017) Age of initiation and internet gaming disorder: the role of self-esteem. Cyberpsychology, Behav Soc Netw 20:397-401. https://doi.org/ 10.1089/cyber.2017.0011

12. Wang TH, Cheng HY (2019) Problematic Internet use among elementary school students: prevalence and risk factors. Inf Commun Soc. https://doi.org/10.1080/1369118X.2019.1645192

13. Organisation for Economic Co-operation and Development (2018) PISA 2018 Technical Report. Paris

14. World Health Organization Cost effectiveness and strategic planning (WHO-CHOICE). https://www.who.int/choice/demography/ euro_region/en/. Accessed 10 Jan 2020

15. von Elm E, Altman DG, Egger M et al (2008) The Strengthening the Reporting of Observational Studies in Epidemiology (STROBE) statement: guidelines for reporting observational studies. J Clin Epidemiol 61:344-349. https://doi.org/10.1016/j.jclin epi.2007.11.008

16. Belanger RE, Akre C, Berchtold A, Michaud P-A (2011) A U-shaped association between intensity of internet use and adolescent health. Pediatrics 127:e330-e335. https://doi.org/10.1542/ peds.2010-1235

17. Camerini AL, Schulz PJ, Jeannet AM (2018) The social inequalities of Internet access, its use, and the impact on children's academic performance: evidence from a longitudinal study in Switzerland. New Media Soc 20:2489-2508. https://doi.org/10.1177/ 1461444817725918

18. Martins MV, Formiga A, Santos C et al (2020) Adolescent internet addiction-role of parental control and adolescent behaviours. Int J Pediatr Adolesc Med 7:116-120. https://doi.org/10.1016/j.ijpam. 2019.12.003

19. Dwairy M, Achoui M (2010) Parental control: a second crosscultural research on parenting and psychological adjustment of children. J Child Fam Stud 19:16-22. https://doi.org/10.1007/ s10826-009-9334-2

20. Liau AK, Khoo A, Ang PH (2008) Parental awareness and monitoring of adolescent Internet use. Curr Psychol 27:217-233. https://doi.org/10.1007/s12144-008-9038-6

21. Yilmaz MB, Orhan F (2010) The use of Internet by high school students for educational purposes in respect to their learning approaches. Procedia Soc Behav Sci 2:2143-2150. https://doi. org/10.1016/j.sbspro.2010.03.296

22. Ha YM, Hwang WJ (2014) Gender differences in internet addiction associated with psychological health indicators among adolescents using a national web-based survey. Int J Ment Health Addict 12:660-669. https://doi.org/10.1007/s11469-014-9500-7

23. Cipolletta S, Malighetti C, Cenedese C, Spoto A (2020) How can adolescents benefit from the use of social networks? The igeneration on instagram. Int J Environ Res Public Health 17:1-15. https://doi.org/10.3390/ijerph17196952

24. Dong H, Yang F, Lu X, Hao W (2020) Internet addiction and related psychological factors among children and adolescents in China during the coronavirus disease 2019 (COVID-19) epidemic. Front Psychiatry 11:1-9. https://doi.org/10.3389/fpsyt.2020. 00751 